\title{
A SUPPLEMENTAL INFORMATION
}
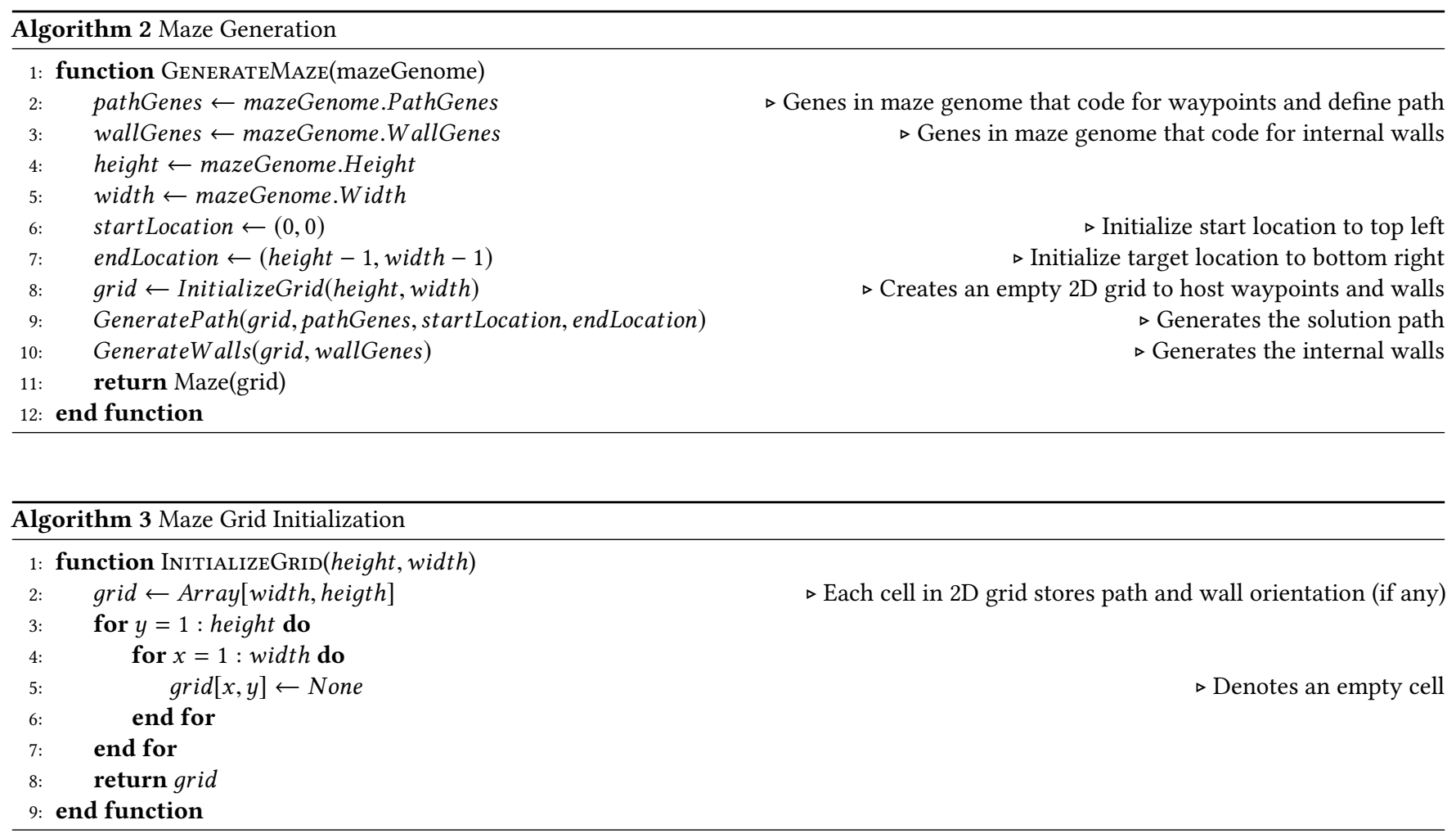


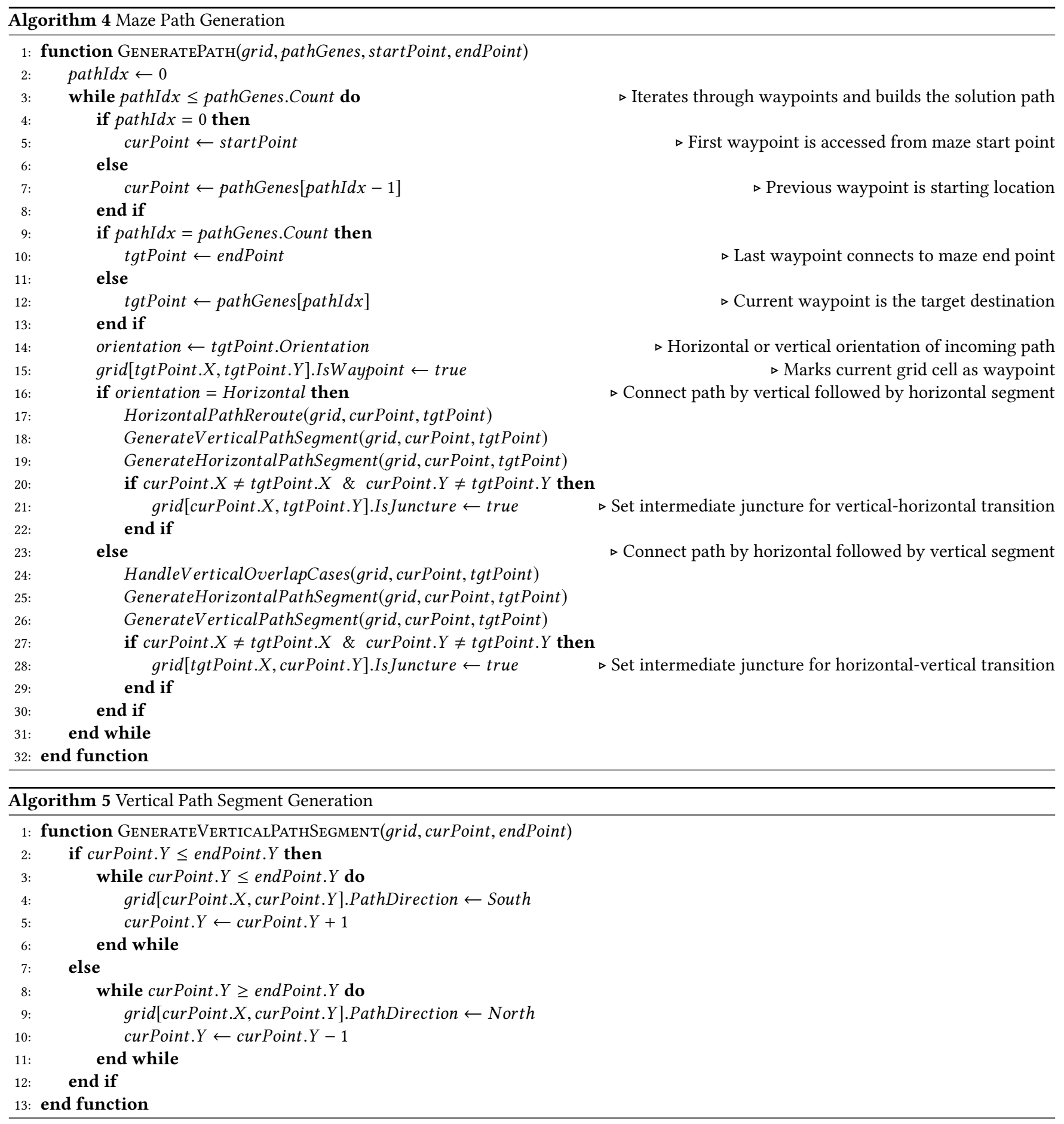



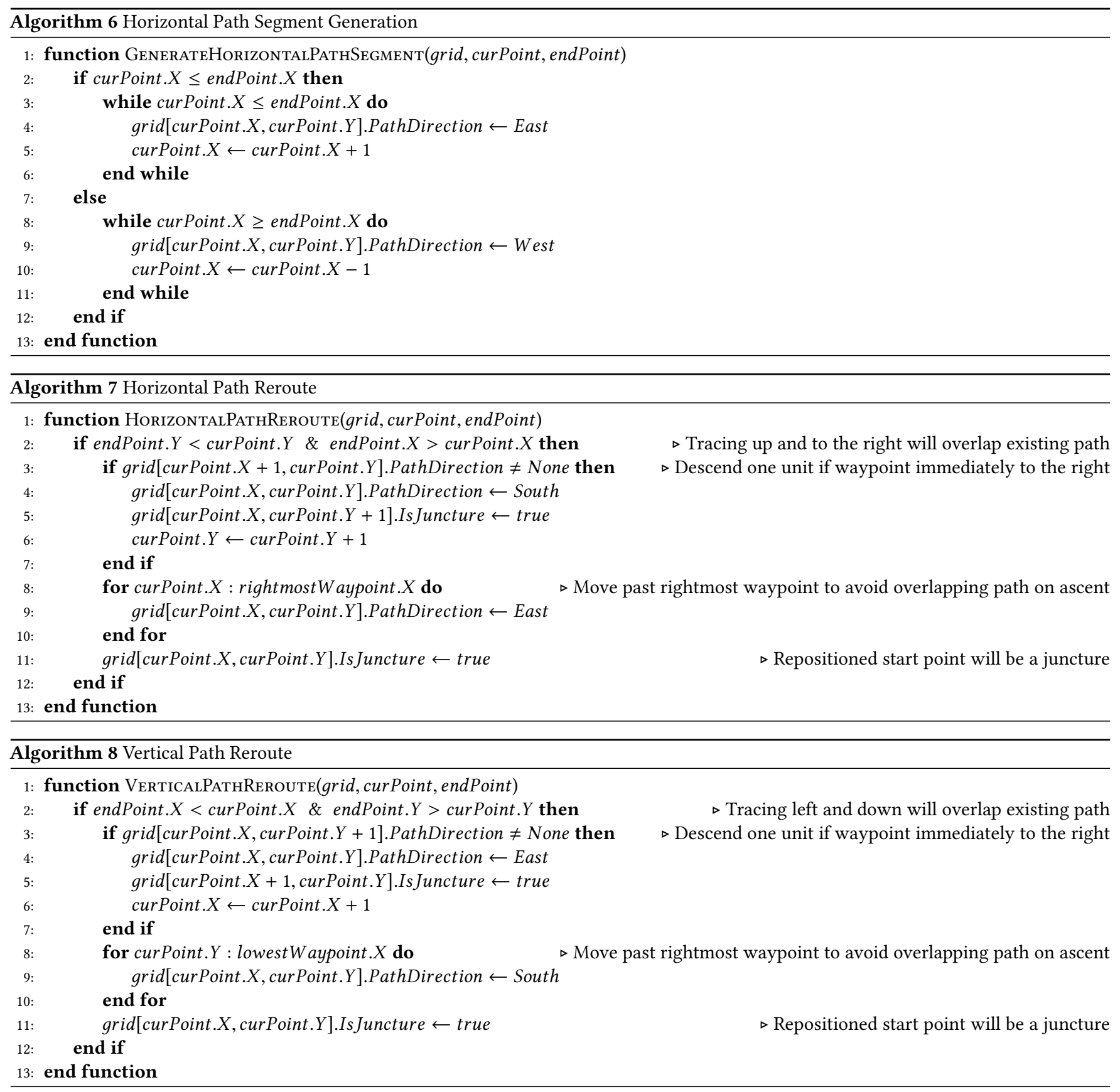


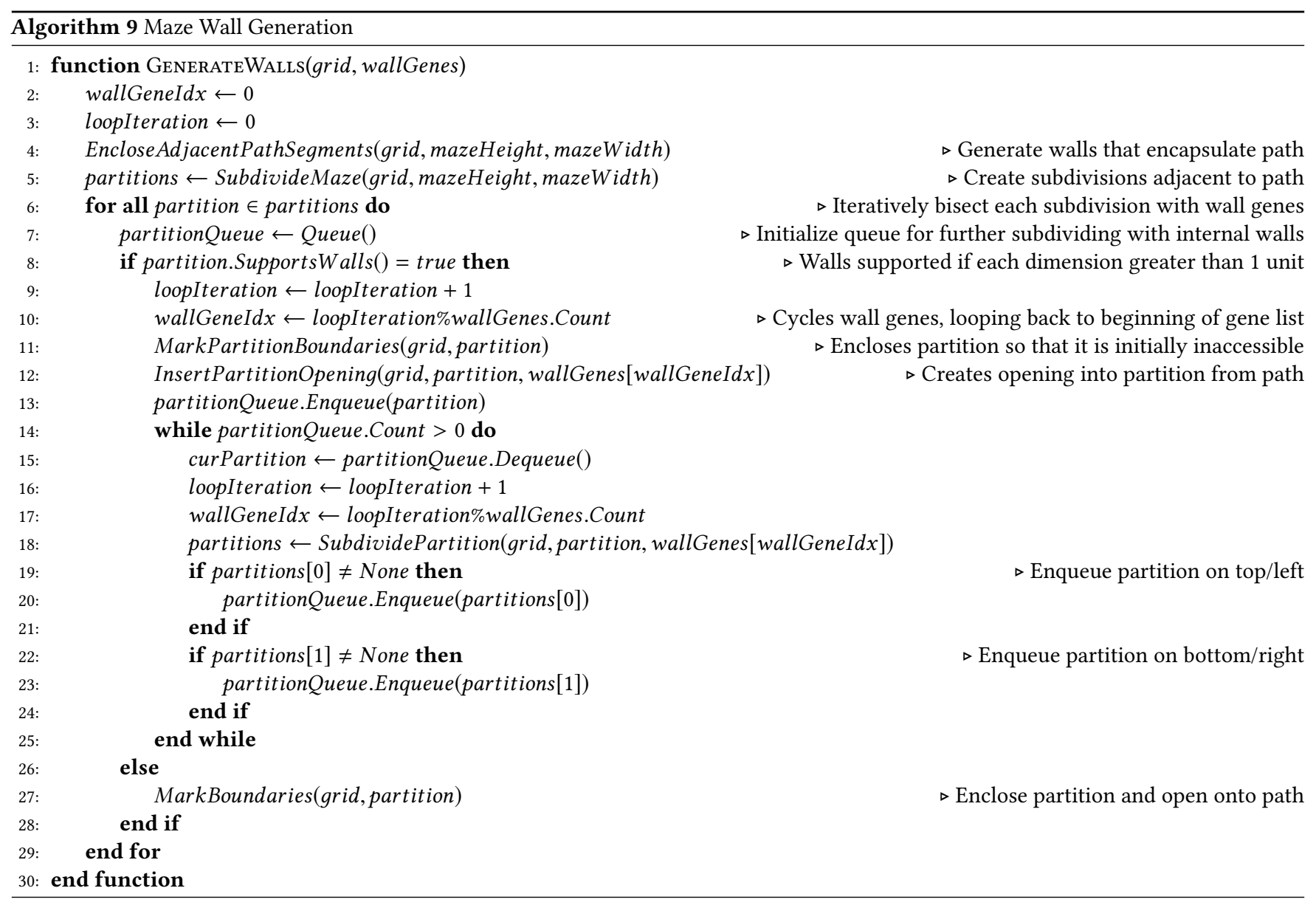




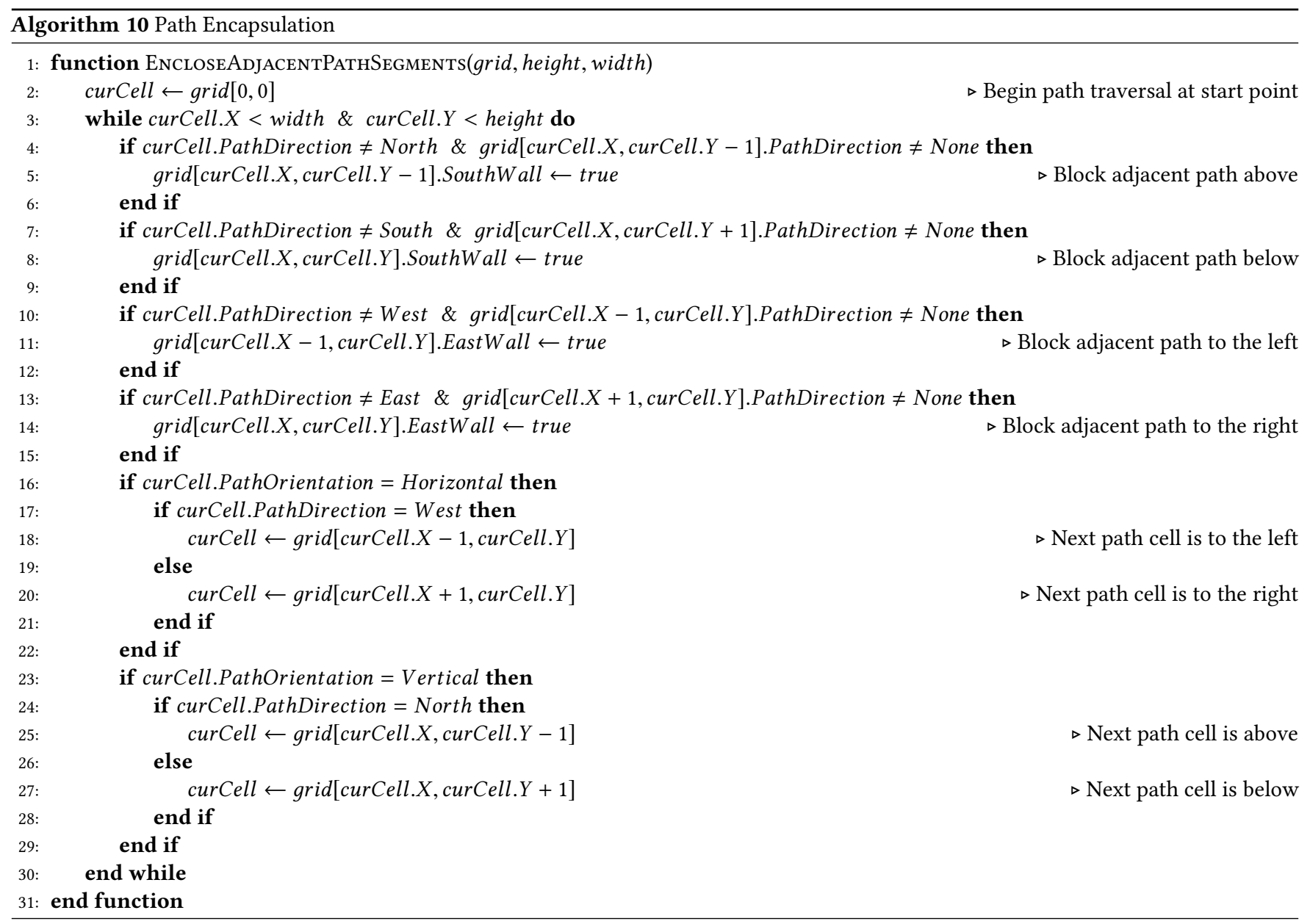



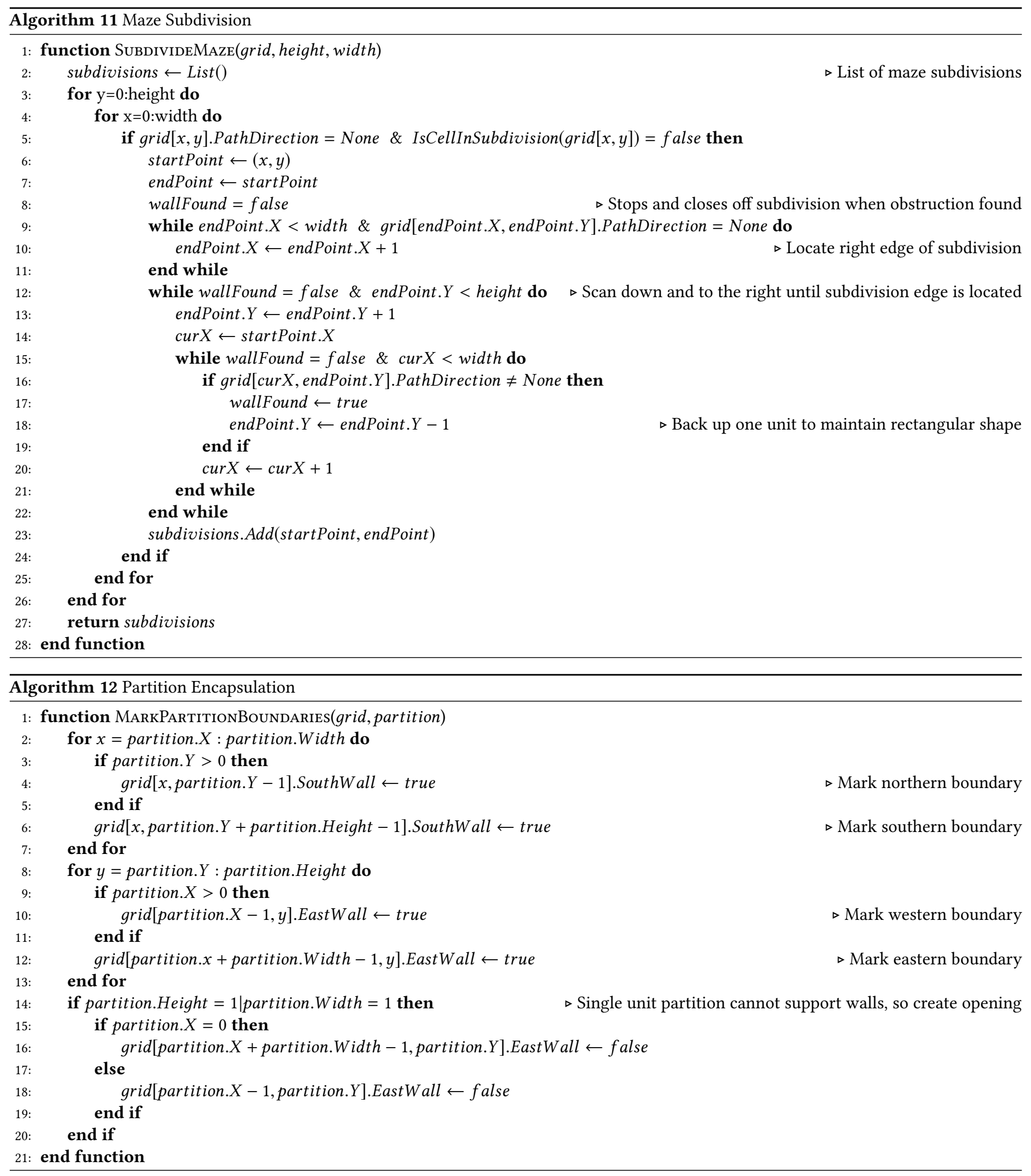


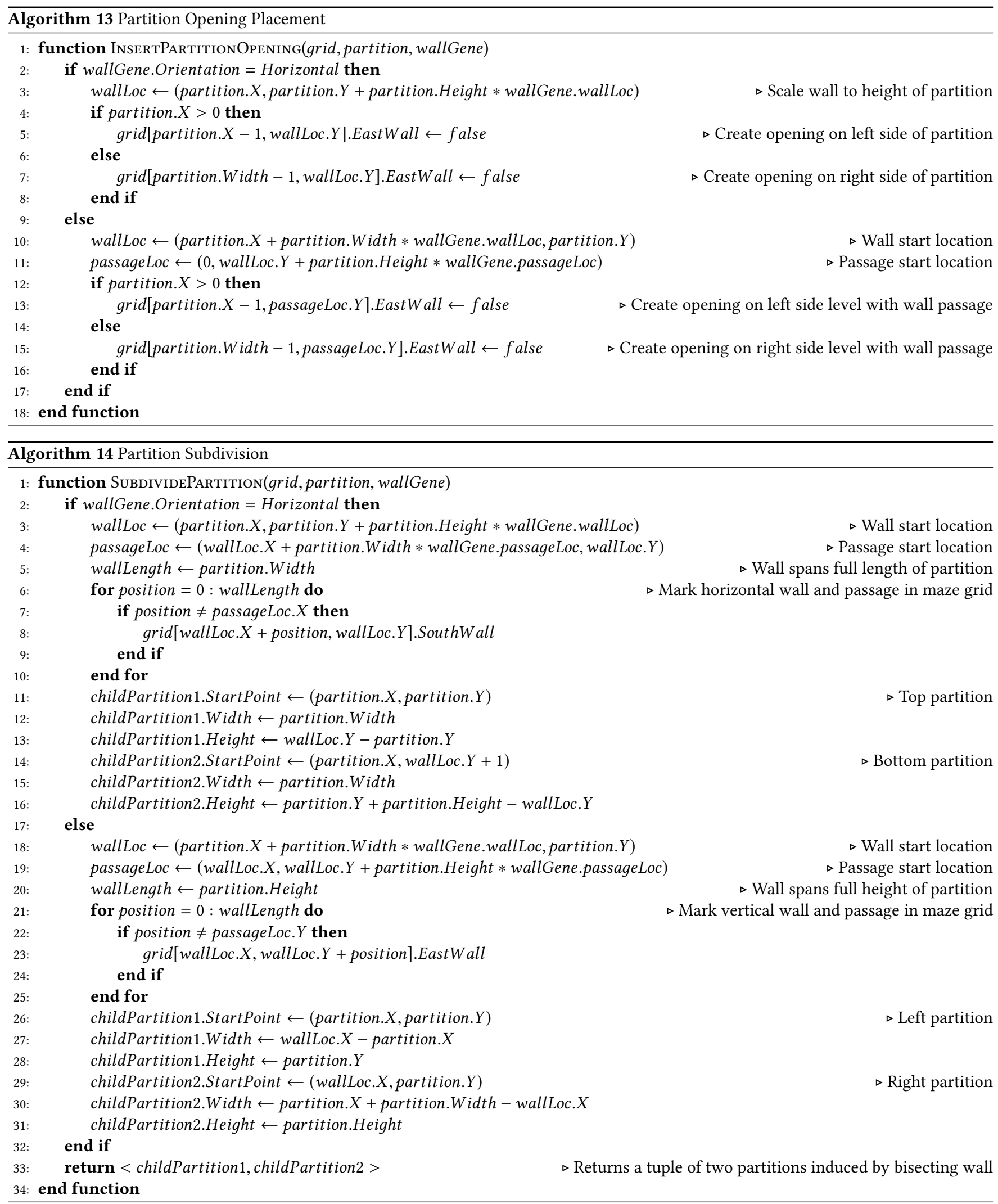

